\title{
ACESSIBILIDADE AOS ESPAÇOS PÚBLICOS DE EAS
}

\author{
OTOCH, Luciana; \\ Universidade de Fortaleza, Especialista \\ e-mail:arqlucianaotoch@yahoo.com.br \\ ROMCY, Cristina; \\ Universidade de Fortaleza, Doutora \\ e-mail:cristinaromcy@unifor.br
}

\begin{abstract}
RESUMO
Mapear a cidade e identificar, dentro dela, onde seriam os melhores lugares para serem implantadas rotas acessíveis é uma tarefa complexa no que diz respeito às diversas alternativas e possibilidades apresentadas. Levar em consideração direitos fundamentais como o direito à cidade e o direito a saúde é uma forma possível de determinar os pontos de origem e destino para a implementação destas rotas. Este artigo versa sobre a importância de tornar acessível o trajeto de deslocamento pedonal aos estabelecimentos assistenciais de saúde (EAS). Define-se como ponto de origem destes trajetos as paradas de ônibus mapeadas e um raio de acesso a ser definido no entorno do EAS e se estabelece uma conexão através da menor distância percorrida entre origem e destino, dando origem as rotas prioritárias a serem adaptadas. Posteriormente faz-se recomendações de análises físicas e qualitativas destes trajetos para uma readequação espacial através da implementação de diretrizes projetuais com a finalidade de transformar estes trajetos em rotas de acessibilidade.
\end{abstract}

Palavras chave: acessibilidade; rotas acessíveis; estabelecimentos assistenciais de saúde.

\begin{abstract}
Mapping the city and identifying within it, where would be the best places to be implemented accessible routes is a complex task with respect to the diverse alternatives and possibilities presented. Taking into account fundamental rights such as the right to the city and the right to health is a possible way of determining the points of origin and destination for the implementation of these routes. This article deals with the importance of making the pedestrian movement path accessible to health care establishments (EAS). It is defined as the origin point of these routes the bus stops mapped and a radius of access to be defined in the surroundings of the EAS and a connection is established through the shortest distance traveled between origin and destination, giving origin to the priority routes to be adapted. Subsequently, recommendations are made for physical and qualitative analysis of these routes for a spatial re-adaptation through the implementation of design guidelines with the purpose of transforming these routes into accessibility routes.
\end{abstract}

Keywords: accessibility; accessible routes; health care establishments.

\section{INTRODUÇÃO}

Muitos estudos apontam para a importância de adequação e estruturação dos estabelecimentos assistenciais de saúde (EAS) quanto ao seu espaço físico de acordo com as normas de acessibilidade. Partindo da premissa de que um EAS deve ser um sistema de 


\section{(x) $^{\text {reace }}$}

saúde aberto, universalizado e equitativo a todos os cidadãos brasileiros, o Ministério da Saúde elaborou em 1994 uma publicação técnica, voltada aos municípios e estados, que versa sobre a normatização de projetos arquitetônicos e de engenharia e a orientações sobre o planejamento de redes físicas de saúde. (Normas para projetos físicos de estabelecimentos assistenciais de saúde- Brasília,1994)

Porém, para assegurar que um EAS seja acessível a todos, faz-se necessário não apenas a sua estruturação interna normatizada, como é fundamental que o acesso espacial urbano ao equipamento seja igualmente elaborado ou adequado espacialmente.

A organização espacial de uma cidade concentrada por diversos usos e o crescimento populacional acelerado das cidades brasileiras nas últimas décadas levantou uma questão que desafia a sociedade e o poder público constituído, a acessibilidade aos espaços urbanos de usos comerciais, de serviços, residenciais, industriais, de lazer, dentre outras que considera o acesso a todas as pessoas e suas diferentes necessidades. A inadequação de boa parte dos espaços públicos no atendimento das necessidades básicas de acesso aos bens e serviços coletivos urbanos por todas as pessoas atinge mais profundamente as Pessoas com Deficiência (PcD) e as Pessoas com Dificuldade de Locomoção (PcDL).

Para elaborar sobre adequação espacial urbana e garantia de acesso democrático aos serviços públicos, faz-se necessário uma breve explanação sobre alguns conceitos básicos como acessibilidade, desenho universal e o espaço público urbano.

\subsection{Acessibilidade e o Desenho Universal}

Segundo a Associação Brasileira de Normas Técnicas 9050 (ABNT, 2015), acessibilidade é a possibilidade e condição de alcance, percepção e entendimento para a utilização com segurança e autonomia de edificações, espaço, mobiliário, equipamento urbano e elemento.

O termo "acessibilidade" surgiu desde o período após a Segunda Guerra Mundial e a guerra do Vietnã, onde os Estados Unidos notaram que não estavam preparados para receber e amparar seus "heróis" de guerra que retornavam ao lar com sequelas físicas e mentais. Era necessária a adaptação urgente dos espaços com a remoção de barreiras físicas. (ORNSTEIN, S.W.; ALMEIDA PRADO, A. R. de; LOPES, M. E., 2010)

Com o intuito de resolver esse problema, surgiu o desenho acessível de projetos, instrumento que respeita a diversidade física e sensorial na concepção de espaços e objetos denominado de Desenho Universal.

O Desenho Universal é resultado de um conceito que trata dos espaços, artefatos e produtos, e visa atender, simultaneamente, a todas as pessoas, com diferentes características antropométricas e sensoriais, de forma autônoma, segura e confortável, constituindo-se nos elementos, ou soluções, que compõem a acessibilidade (BRASIL, 2004).

O termo Universal Design foi criado em 1987 pelo americano Ron Mace, arquiteto que usava cadeira de rodas e um respirador artificial. De acordo com o seu pensamento, não se tratava do nascimento de uma nova ciência ou estilo, mas, sim, de uma percepção de aproximação das coisas projetadas, tornando-as utilizáveis por todas as pessoas. $O$ Desenho Universal não tratava apenas da remoção de barreiras, ele ia além, defendia a concepção espacial sem barreiras. (ORNSTEIN, S.W.; ALMEIDA PRADO, A. R. de; LOPES, M. E., 2010)

De acordo com Cambiaghi (2007), os sete princípios do desenho universal são:

1 - Equiparações nas possibilidades de uso: O desenho universal não é elaborado para grupos específicos de pessoas, devendo, assim, atender a todos os grupos. (...) 


\begin{abstract}
uma ampla gama de indivíduos, preferências e habilidades.[...] 3 - Uso simples e intuitivo: $O$ desenho universal tem o objetivo de tornar o uso facilmente compreendido, independentemente da experiência do usuário, do seu nível de formação, conhecimento do idioma ou de sua capacidade de concentração. [...]

4 - Informação perceptível: O desenho universal tem o objetivo de comunicar eficazmente aos usuários as informações necessárias, independentemente das condições ambientais ou da capacidade sensorial deste. [...]

5 - Tolerância ao erro: $O$ desenho universal tem o objetivo de minimizar o risco e as consequências de ações acidentais. [...]

6 - Mínimo esforço físico: O desenho universal prevê a utilização, de forma eficiente e confortável, com o mínimo de esforço. [...]

7 - Dimensionamento de espaço para acesso e uso de todos os usuários: 0 desenho universal tem o objetivo de oferecer espaços e dimensões apropriados ao uso, independentemente do tamanho ou da mobilidade do usuário. (Cambiaghi, 2007, p. 73-78).
\end{abstract}

É um desenho, portanto, para todas as pessoas que deve ser adotado na criação de espaços e objetos a fim de garantir igualdade de condição desde a sua concepção.

\title{
1.2 Acessibilidade e o espaço público urbano
}

A acessibilidade se aplica tanto as pessoas com deficiência quanto a outros grupos de pessoas com mobilidade reduzida: aquelas que têm necessidades especiais de receberem determinadas informações ou de se deslocarem através das vias urbanas e dos meios coletivos de transporte, devido a alguma limitação em função da idade, estado de saúde, estatura, obesidade, deficiências e outras condicionantes (Ministério das Cidades, 2004).

Para Cohen e Duarte (2001, p.2),

a delimitação adequada do conceito de acessibilidade reside no seu potencial de gerar novos paradigmas para o planejamento de espaços, bem como para a reflexão e abordagem de uma temática que tem estado tão presente em discussões onde se buscam respostas para os inúmeros problemas hoje encontrados nas cidades por pessoas com deficiência.

De acordo com Gomes (2002, p.162) entende-se como espaço público o lugar, praça, rua, shopping, praia, qualquer tipo de espaço, onde não haja obstáculos à possibilidade de acesso e participação de qualquer tipo de pessoa... Essa acessibilidade é física, mas também diz respeito ao fato de que não deve estar condicionada à força de quaisquer outros critérios senão daqueles impostos pela lei que regula os comportamentos em áreas comuns.

\section{DIREITOS FUNDAMENTAIS}

Para entender sobre democratização espacial e justificar como prioridade de adequação espacial urbana às normas de acessibilidade o trajeto de deslocamento a estabelecimentos assistenciais de saúde é preciso compreender que tanto o direito a cidade quanto o direito a saúde são direitos fundamentais garantidos pela Constituição Federal de 1988, onde os Direitos Fundamentais são definidos como conjunto de direitos e garantias do ser humano institucionalização, cuja finalidade principal é o respeito a sua dignidade, com proteção ao poder estatal e a garantia das condições mínimas de vida e desenvolvimento do ser 


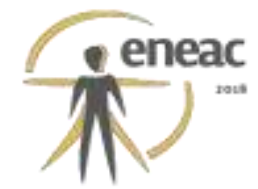

humano, visando garantir ao ser humano, o respeito à vida, à liberdade, à igualdade e a dignidade, para o pleno desenvolvimento de sua personalidade.

\subsection{Direito à cidade}

Para Lefebvre ([1968] 2008) o direito à cidade se refere a uma sociedade diferente, onde a lógica de produção do espaço urbano esteja subordinada ao valor de uso e não ao valor de troca. Ele acredita que o direito a cidade seria o direito

"[...] à vida urbana, à centralidade renovada, aos locais de encontro e de trocas, aos ritmos de vida e empregos do tempo que permitem o uso pleno e inteiro desses momentos e locais etc. [...]. A proclamação e a realização da vida urbana como reino do uso (da troca e do encontro separados do valor de troca) exigem o domínio do econômico (do valor de troca, do mercado e da mercadoria) [...]" (Lefebvre, [1968] 2008, p. 139).

Tomando-se como referência a legislação brasileira atual, na Lei $n^{\circ} 10.257 / 2001$, conhecida como Estatuto da Cidade, que regulamenta os artigos 182 e 183 da Constituição Federal, e tem como base o seguinte objetivo: "Para todos os efeitos, esta Lei, denominada Estatuto da Cidade, estabelece normas de ordem pública e interesse social que regulam o uso da propriedade urbana em prol do bem coletivo, da segurança e do bem-estar dos cidadãos, bem como do equilíbrio ambiental" (Brasil, 2001), conclui-se que a função social nada mais é do que a sobreposição do interesse público em relação ao interesse privado na prática de uma atividade, para promover assim a inclusão social.

Para Sassaki, a inclusão social é

"[...] o processo pelo qual a sociedade se adapta para poder incluir, em seus sistemas sociais gerais, pessoas com necessidades especiais e, simultaneamente, estas se preparam para assumir seus papéis na sociedade. A inclusão social constitui, então, um processo bilateral no qual as pessoas, ainda excluídas, e a sociedade buscam, em parceria, equacionar problemas, decidir sobre soluções e efetivar a equiparação de oportunidades para todos." (SASSAKI, 1997, p. 41)

A arquitetura cumpre sua função social quando sua prática gera resultados significativos para a construção do bem comum. Portanto, a função social precisa estar inserida nas ponderações referidas a ocupação do espaço urbano, para que se possa nortear que tipo de cidade é desejada e consequentemente que tipo de sociedade se quer.

\subsection{Direito à saúde}

$\mathrm{Na}$ Constituição Federal o direito à saúde teve grande destaque sendo qualificado como um direito social (art. 6o), e um direito humano fundamental. Instituiu-se a responsabilidade comum da União, dos estados, do Distrito Federal e dos municípios para implementarem as políticas públicas (CF, art. 23, II), qualificando a saúde como um direito de todos e dever do Estado, a ser garantido mediante políticas públicas que assegurem o acesso universal e igualitário (art. 196), com atendimento integral (art. 198, II). Tais garantias foram reafirmadas pelo art. $2^{\circ}$ da Lei Orgânica da Saúde (Lei nº 8.080/1990).

O acesso universal deve ser compreendido não apenas no sentido de que se assegure à universalidade de pessoas o acesso aos serviços de saúde, garantindo a igualdade de oportunidades para tratamentos, como também garantindo que o deslocamento ao EAS seja espacialmente acessível a todos. 


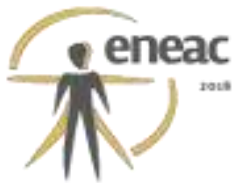

\section{ACESSO AOS ESTABELECIMENTOS ASSISTENCIAIS DE SAÚDE}

Na busca de uma forma democrática de deslocamento no sistema viário urbano encontra-se a utilização do transporte público como ferramenta de transporte de maior alcance populacional.

Atualmente, de acordo com o Programa de Transporte Urbano de Fortaleza, a cidade apresenta uma malha viária estimada $3.887 \mathrm{~km}$ de extensão linear, com traçado ortogonal, porém com eixos principais espalhando-se radialmente em direção ao bairro do Centro.

A mobilidade em Fortaleza é garantida por quatro serviços de transporte público: o serviço de transporte coletivo por ônibus (STCO), o sistema de transporte público complementar (STPC), o sistema de táxi e de mototáxi. Esses sistemas são geridos pela administração municipal através da Empresa de Transporte Urbano de Fortaleza, a ETUFOR.

O sistema de transporte coletivo por ônibus do Município de Fortaleza divide-se em dois subsistemas: o SITFOR e o sistema Seletivo.

- O SITFOR é o Sistema Integrado de Transportes de Fortaleza que compreende o transporte por ônibus com integração física, temporal e tarifária.

- O sistema Seletivo é composto por duas linhas voltadas para o atendimento basicamente turístico.

O Sistema Integrado de Transportes de Fortaleza entrou em operação em 1992 com fins de proporcionar o deslocamento através da integração tarifária e física em terminais de integração. A rede de linhas do SITFOR baseia-se numa configuração de sistema tronco alimentado contando com dois tipos básicos de linhas: as que fazem a integração bairroterminal (linhas alimentadoras) e as que integram um terminal ao Centro (linhas troncais).

\subsection{Origem e destino}

Para garantir o acesso através do sistema público de transporte aos EAS, precisa-se definir a origem de trajeto do usuário do sistema de saúde tendo como destino final o equipamento de saúde.

Sabe-se que o usuário de transporte coletivo por ônibus encerra a utilização de seu deslocamento motorizado em pontos específicos da cidade denominados de pontos de parada de ônibus. A chegada a esse ponto de parada, próximo ao local de destino do deslocamento dá início a outro tipo de deslocamento denominado deslocamento pedonal.

Neste trajeto de deslocamento, a caminhabilidade (walkability), que consiste em melhores condições do espaço urbano sob a ótica do pedestre, passa a ser condição fundamental para o alcance do destino.

Uma vez entendido que a origem do trajeto se dá através do elemento denominado parada de ônibus, tendo como destino final um EAS, faz-se necessário estabelecer um raio de atuação que será implantado para o devido mapeamento das principais paradas de ônibus nas proximidades do local de destino.

Da ligação entre cada local de origem (paradas de ônibus) e seu destino (EAS), por meio de deslocamento pedonal, surgem as rotas prioritárias a serem trabalhadas e adaptadas através dos conceitos e normas de acessibilidade, com a principal finalidade de garantir a população o acesso aos estabelecimentos assistências de saúde, preservando-lhes assim o direito a cidade e a saúde. 


\section{(ame $^{\text {reme }}$}

\subsection{Critério de definição e avaliação de rotas}

Existem formas diversas de ligação entre um ponto de origem e um destino, isto vai depender dos elementos utilizados como parâmetros para este deslocamento, como por exemplo: a menor distância, o trajeto com maior fluxo de pedestres, o deslocamento com maior arborização, com mais paisagens contemplativas, etc. Partindo da premissa de que o deslocamento pedonal por parte de pessoas que tem como destino um tratamento de saúde deve-se dá pelo fator de menor tempo de deslocamento, consequentemente, menor distância, tem-se este como o principal critério de ligação origem-destino.

Ao avaliar uma rota podem-se utilizar critérios tanto físicos quanto qualitativos. Os critérios físicos são definidos através de parâmetros que proporcionem um mínimo necessário de acessibilidade que garanta a mobilidade de pedestres. No Brasil a NBR 9050 (ABNT, 2015) intitulada "Acessibilidade a edificações, mobiliário, espaços e equipamentos urbanos" estabelece critérios e parâmetros técnicos de projeto, construção, instalação e adaptação às condições de acessibilidade dos espaços a que se refere.

Quanto aos critérios qualitativos de avaliação, estes se dão a partir da interação entre o indivíduo e o meio ambiente que o circunda. Os métodos de avaliação qualitativa estão, segundo Ferreira \& Sanches (2001), diretamente ligados aos níveis e tipos de serviços oferecidos pelo espaço urbano em questão, ou seja, ao caminhar, o pedestre está sujeito a uma diversidade de fatores que afetam de forma significativa o seu sentimento de conforto, segurança e conveniência.

\subsection{Rotas acessíveis}

Definida e analisada as rotas de acesso aos EAS, para a obtenção de um trajeto ideal por parte do pedestre faz-se necessário transformá-las em rotas acessíveis, ou rotas de acessibilidade.

Encontra-se na NBR 9050 (2015, p. 54) a seguinte definição para rota acessível:

A rota acessível é um trajeto contínuo, desobstruído e sinalizado, que conecta os ambientes externos e internos de espaços e edificações, e que pode ser utilizada de forma autônoma e segura por todas as pessoas. A rota acessível externa incorpora estacionamentos, calçadas, faixas de travessias de pedestres (elevadas ou não), rampas, escadas, passarelas e outros elementos da circulação. A rota acessível interna incorpora corredores, pisos, rampas, escadas, elevadores e outros elementos da circulação.

Na cidade de Fortaleza o Plano de Caminhabilidade, que consiste em um plano municipal que tem como objetivo incentivar os deslocamentos a pé, por meio da qualificação dos passeios nas calçadas, garantindo a completude nos bairros, relacionando moradia e trabalho, ainda está em fase de elaboração, porém outras cidades já possuem legislação e planejamento sobre o tema.

Ao tornar as cidades acessíveis através de um plano de rotas acessíveis promove-se a inclusão e evitam-se obras desconexas e descontinuas. 


\section{(x) $^{\text {reace }}$}

\subsection{Diretrizes projetuais para adequação de rotas quanto a acessibilidade}

Diretrizes projetuais são instruções e orientações que definem os critérios e parâmetros para o desenvolvimento de um projeto.

Para a elaboração de diretrizes projetuais de planejamento faz-se necessário inicialmente um mapeamento do problema em análise e em seguida um grande estudo de possíveis ideias para solucionar os problemas. Estas ideias devem ser testadas em pequenas proporções, em projetos pilotos e posteriormente, garantido seu sucesso, aplicadas em grandes projetos de intervenção urbana.

No Brasil obtêm-se diversos instrumentos legais visando favorecer a questão da acessibilidade e da mobilidade urbana. Na esfera federal, quatro deles merecem destaque: a Constituição Federal Brasileira de 1998; a Lei 10.257/01, denominada Estatuto da Cidade, instrumento que regulamenta os artigos 182 e 183 da Constituição Brasileira, estabelecendo diretrizes gerais para a política urbana, visando ordenar o pleno desenvolvimento das funções sociais da cidade e da propriedade urbana; o Decreto 5.296/04, que regulamenta as Lei $\mathrm{n}^{\circ} 10.048$, de 8 de novembro de 2000, que dá prioridade de atendimento às PCD e a Lei no 10.098, de 19 de dezembro de 2000, que estabelece normas gerais e critérios básicos para a promoção da acessibilidade. Acrescente-se também a NBR 9050 (2015), já mencionada anteriormente.

Levando-se em consideração essa diversidade de instrumentos legais instituídos, podem-se listar as seguintes diretrizes como bases de projeto de planejamento sustentável para espaços públicos com acessibilidade:

- Priorizar o fluxo de pedestres.

- Definir calçadas, caminhos e travessias, privilegiando o acesso universal e com o menor risco para a saúde e integridade física.

- Projetar as calçadas com faixas de serviços para locação de postes, árvores, cestos de lixo, telefone público e demais equipamentos, separadas da faixa livre sinalizada para o fluxo de pessoas.

- Implementar as informações de orientação utilizando os recursos adequados (tátil, sonoro e visual) aos diferentes tipos de usuários e ordená-las em grau de importância.

- Considerar a longevidade no uso dos espaços, ambientes e produtos por todo o ciclo de vida de um ser humano, da infância à idade avançada, sem a necessidade de mudanças estruturais.

- Possibilitar o uso dos espaços com eficiência máxima e fadiga mínima, permitindo ao usuário sentir-se confortável durante o deslocamento.

- Incentivar a criação de áreas verdes e áreas permeáveis, com uso de espécies de grandes copas e sombra densa nas regiões quentes, principalmente nos passeios

- Privilegiar a implantação da vegetação nos passeios junto a muros, canteiros centrais, rotatórias, áreas permeáveis, áreas de preservação permanentes, praças e parques.

- Privilegiar o uso de transportes pouco ou não poluentes e fornecer condições adequadas ao seu uso.

- Limitar o número de vagas de estacionamento ao mínimo exigido pela legislação municipal, estimulando assim um deslocamento mais sustentável.

O foco do desenvolvimento urbano sustentável é a busca de melhores condições de vida perdidas ou prejudicadas pelo crescimento urbano desordenado. Através dessas diretrizes pode-se pensar o espaço público de forma mais democrática, implantando nos 


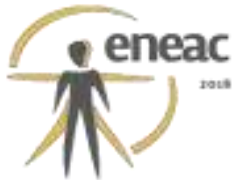

projetos de intervenção urbana princípios primordiais para uma maior inclusão social no espaço das cidades.

\section{CONCLUSÃO}

Apesar de muitos estudos apontarem a necessidade de adequação e estruturação dos estabelecimentos assistenciais de saúde (EAS) quanto ao seu espaço físico de acordo com as normas de acessibilidade, pouco se questiona em quais condições de deslocamento urbano o indivíduo é inserido para acessar estes estabelecimentos.

Os meios adequados de se chegar a um EAS são tão significativos quanto a sua estruturação interna acessível. Através da implementação espacial de conceitos como acessibilidade e desenho universal, pode-se assegurar de forma mais concisa os direitos fundamentais do cidadão como o direito à cidade e o direito a saúde.

Através da adoção do transporte coletivo por ônibus como ferramenta de transporte de maior alcance populacional é possível se determinar as paradas de ônibus como origens de rotas cujo destino final é um EAS. Ao mapear estes pontos de partida em um raio de atuação no entorno da EAS e ligá-los ao estabelecimento de destino utilizando o critério de menor distância de locomoção, define-se as rotas de trajeto pedonal prioritárias a serem trabalhadas e adaptadas.

Uma vez definidas as rotas prioritárias de acesso a um EAS em um determinado raio de atuação pré-estabelecido, devem-se estudar os percursos através de análise física e qualitativa para uma melhor adaptação espacial seguindo diretrizes projetuais que tenham por finalidade transformar estes trajetos em rotas de acessibilidade.

Ao tornar as cidades acessíveis promove-se a democratização espacial, tornando o espaço público cada vez mais inclusivo.

\section{REFERÊNCIAS BIBLIOGRÁFICAS}

(1990) Lei 8.080 de 19 de setembro de 1990: Dispõe sobre as condições para a promoção, proteção e recuperação da saúde, a organização e o funcionamento dos serviços correspondentes e dá outras providências. Brasília: Congresso Nacional.

(2001) Lei 10.257 de 10 de julho de 2001: Regulamenta os artigos 182 e 183 da Constituição Federal, estabelece diretrizes gerais da política urbana e dá outras providências. Brasília: Congresso Nacional.

ASSOCIAÇÃO BRASILEIRA DE NORMAS TÉCNICAS - ABNT. NBR 9050/15: Acessibilidade a edificações, mobiliário, espaços e equipamentos urbanos. São Paulo: ABNT, 2015.

BRASIL. Constituição (1988). Constituição da República Federativa do Brasil. Brasília, DF: Senado Federal: Centro Gráfico, 1988. 292 p.

BRASIL (2004) Decreto no 5.296, de 02 de dezembro de 2004. Regulamenta as Leis nos 10.048 , de 8 de novembro de 2000, que dá prioridade de atendimento às pessoas que especifica, e 10.098, de 19 de dezembro de 2000, que estabelece normas gerais e critérios básicos para a promoção da acessibilidade das pessoas portadoras de deficiência ou com mobilidade reduzida, e dá outras providências. Brasília.

BRASIL. Ministério da Saúde. Secretaria de Assistência à Saúde. Normas para projetos físicos de estabelecimentos assistenciais de saúde.- Brasília,1994 - 136 p ( Série: Saúde \& Tecnologia)

CAMBIAGHI, Silvana (2007) Desenho universal: Métodos e Técnicas para Arquitetos e Urbanistas/ Silvana Cambiaghi. São Paulo: Editora Senac São Paulo, 2007. 


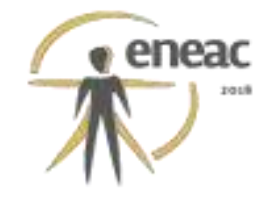

COHEN, Regina; DUARTE, Cristiane Rose. Subsídios para o planejamento de acessibilidade aos espaços urbanos. Belo Horizonte, 2001. In: Anais do II Seminário Internacional Sociedade Inclusiva, PUC-Minas

FERREIRA, M. A. G.; Sanches, S. P. (2001) Índice de Qualidade das Calçadas - IQC. Revista dos Transportes Públicos - ANTP. São Paulo. Ano 23. 20 trim. ํo 9. Pp. 47-60.

GOMES, Paulo César da Costa. A condição urbana: ensaio de geopolítica da cidade. Rio de Janeiro: Bertrand Brasil, 2002. 304p.

LEFEBVRE, H. [1968] 2008. O direito à cidade. São Paulo: Centauro.

MINISTÉRIO DAS CIDADES - Secretaria Nacional de Transporte e da Mobilidade Urbana. Manual de Referência para a Acessibilidade de Pessoas com Restrição de Mobilidade, Brasília, DF, jun. 2004.

ORNSTEIN, S.W.; ALMEIDA PRADO, A. R. de.; LOPES, M. E. (Orgs). Capitulo 01 - Conceituação e Procedimentos Metodológicos. In: Desenho Universal: caminhos da acessibilidade no Brasil. pp 33 a 127. São Paulo: Annablume, 2010.

SASSAKI, Romeu Kasumi. Inclusão: construindo uma sociedade para todos. 5. ed. Rio de Janeiro: VWA, 1997. 176p. 